\title{
Maternal Stress and the Functions of Positivity in Mothers of Children with Intellectual Disability
}

\author{
Mikeda Jess ${ }^{1} \cdot$ Vasiliki Totsika $^{1} \cdot$ Richard P Hastings ${ }^{1}$
}

Published online: 20 July 2018

(c) The Author(s) 2018

\begin{abstract}
Although mothers raising children with Intellectual Disability (ID) report poorer mental health than parents raising typically developing children, they also report feelings of positivity; both generally and specific to their child. To date little is known about the function of maternal positivity thus, we explored the putative compensatory and protective functions of maternal positivity, within both a cross-sectional and one-year longitudinal framework that examined the relationship between children's behaviour and mental health problems with maternal mental health problems. Participants included 135 mothers of children with severe ID who were between 3 and 18 years of age. Multiple linear regression models investigated the potential function of maternal positivity. At a cross-sectional level, maternal positivity was found to be a significant independent predictor of maternal stress and moderated the impact of child behaviour problems on maternal parenting stress. Longitudinally, maternal positivity did not have a direct effect on later parenting stress nor function as a moderator. Findings from our cross-sectional analysis are consistent with the view that positivity serves a compensatory function. Further exploration is needed to understand the longitudinal function of maternal positivity.
\end{abstract}

\section{Introduction}

High quality population-based research data suggest that mothers raising children with intellectual disabilities (ID) experience higher levels of stress and mental health problems compared to other mothers (Emerson 2003; Emerson and Llewellyn 2008; Totsika et al. 2011). Despite the difficulties and challenges, many parents of children with ID are able to thrive and express a positive attitude towards life (Blacher and Baker 2007; Gardner and Harmon 2002) and their child (Hastings and Taunt 2002; Hastings et al. 2002). Thus, the question of whether parents are affected negatively by raising a child with ID involves a complex answer: they do face more stress, but they also report significant positive outcomes and positive well-being often to the same extent as do other parents (Hastings 2016).

There has been an increase of research focussing on positive constructs and outcomes for parents of children

Mikeda Jess

m.jess@warwick.ac.uk

1 Centre for Educational Development, Appraisal and Research (CEDAR), University of Warwick, Coventry CV4 7AL, UK with ID, particularly mothers. In a majority of cases the primary carer of children in any family is the mother. Therefore, any adverse or beneficial effects associated with raising a child would arguably have a greater salience for the mother-more so than for other family members. Lloyd and Hastings (2009) explored hope (defined as one's perceived ability to reach a goal) and its relationship with parental well-being. It was found that mothers of children with ID who reported higher levels of hope reported lower levels of anxiety, depression and stress. Other positive constructs such as life satisfaction and positive affect have also been found to have negative associations with parenting stress and depression (Ekas et al. 2010; Lloyd and Hastings 2009).

Disability-specific measures of positive experiences have been developed for parents of children with ID, including the Positive Gain Scale (Griffith et al. 2011; Jones et al. 2014; MacDonald et al. 2010; Pit-ten Cate 2003; Weiss et al. 2015), the Positive Contributions Scale (Behr et al. 1992; Hastings et al. 2002; Hastings et al. 2005a; Vilaseca et al. 2014) and the Positive Impact scale of the Family Impact Questionnaire (FIQ; Donenberg and Baker 1993). Evidence suggests not only that positivity exists within these families but in some instances children with ID may have a more positive impact on their family than typically 
developing children have on theirs (Blacher et al. 2013). In addition, existing research indicates that such positive constructs often have a distinct inverse relationship with negative outcome measures (Hastings et al. 2005b; Lloyd and Hastings 2008; Minnes et al. 2015; Vilaseca et al. 2014).

Less research attention has been given to the putative functions of positive perceptions and positive functioning for parents of children with ID. In an early review of parental positivity in developmental disabilities, Hastings and Taunt (2002) drew on risk and resilience theories (Fraser et al. 1999; Luthar 1991; Luthar and Zigler 1991; Rutter 1985) to identify potential different functions of positivity. Resilience has been described as the ability to thrive despite exposure to adversity or stressful life events (Luthar 1991), and as the ability to withstand stress (Heiman 2002). In ID research, a resilience perspective is related to the considerable external and child-related challenges when raising a child with ID and the fact that many parents and families thrive despite these stressors. To be able to consider the functions of positivity, it is also necessary first to clarify a reliable stressor for parents of children with ID. Stressors would ideally be evidenced as risk factors, variables causally related to parental well-being. The behaviour problems of children with ID is the most consistently identified risk factor for poorer parental well-being in families of children with ID. Several longitudinal research studies show that child behaviour problems are a significant predictor of later poorer parental mental health (Baker et al. 2003; Herring et al. 2006; Lounds et al. 2007; Neece and Baker 2008; Neece et al. 2012).

Luthar (1991) outlined resilience variables as serving two distinct functions: compensatory and protective. Variables which function as protective moderate the effects of life stressors. Protective factors improve outcomes in the face of stressors (i.e., risk) but not necessarily otherwise. Within the context of ID research, the stressor, or risk variable could be child behaviour problems. Positive constructs would have a protective function if when exposed to high levels of child behaviour problems those with high levels of positivity were less affected in terms of their mental health than those with lower levels of positivity. A compensatory function is a main effect as opposed to an interactive/moderating effect. In the current case, positivity would serve a compensatory function if high levels of positivity predicted better maternal mental health. However, this relationship would be independent of any association with child behaviour problems as a risk factor. In a recent cross-sectional study Halstead et al. (2018) explored whether maternal resilience, defined by The Brief Resilience Coping Scale (Sinclair and Wallston 2004), had either a protective or compensatory function for mothers of children with ID when child emotional and behavioural problems functioned as risk factors. The study found strong support for a compensatory function, with maternal resilience having a direct effect on maternal anxiety, depression and parenting stress. However, maternal resilience was found to have only a slight protective function for maternal stress only thus it was concluded that higher levels of resilience were associated with better maternal outcomes.

Although not directly referring to either compensatory or protective effects, existing research has examined both of these potential functions within single indicators of parental positivity in families of children with developmental disabilities. The interest in maternal positivity in these families brings together two perspectives. The first is a theoretical orientation towards strengths-based approaches in ID research (Wehmeyer et al. 2017). This approach advocates a research focus on strengths, which is consistent with cumulative evidence that families of children with ID can experience positive adaptation, despite any negative outcomes (Hastings 2016). The second perspective that informed the focus of this study was the evidence from family research in typical development that different dimensions of parenting or parental well-being (positive and negative) are correlated with different outcomes in children (Anthony et al. 2005; Benzies et al. 2004; Hautmann et al. 2015; Morgan et al. 2002; Salari et al. 2014). Similarly, current evidence in ID research supports a small positive association between positive parenting and child outcomes (Dyches et al. 2012), but it is unclear how maternal positivity (i.e., a psychological state of positive orientation) is associated with other aspects of maternal mental health and also child outcomes in this population. For example, there is a negative association between maternal self-efficacy (one of the aspects of the positivity construct, as detailed below) and maternal mental health problems (Hassall et al. 2005; Hastings and Brown. 2002; Kuhn and Carter. 2006). In terms of a putative protective function for parental positivity, Weiss et al. (2015) found that high levels of child aggression in children with Autism Spectrum Disorder (ASD) were not related to distress in mothers who also reported high rates of positive gain. Previous cross-sectional studies of families raising children with ID and or ASD have also identified different variables that could be considered indicators of positivity, such as positive impact, and positive reappraisal coping styles that have moderated the relationship between stressors and parental mental health (Blacher and Baker 2007; Dunn et al. 2001; Glidden et al. 2006; Lyons et al. 2010).

Existing research on the function of parental positivity has been largely limited to cross-sectional studies. Even within longitudinal studies, the prospective nature of the available data has not been reported. For example, parental 
optimism moderated the relationship between child behaviour problems and parental depression (primarily for mothers) in families of young children with ID when the child was three years old and also when the child was four years old (Baker et al. 2005). Although this study demonstrates that optimism functioned as a moderator at two time points within the same sample, the results do not determine whether parental optimism, when the child was three, would moderate the impact of child behaviour problems (at three years old) on later parental depression (one year later). Thus, the function of optimism over time was not explored. To fully examine either a compensatory or protective function, prospective research designs are needed: positivity may reduce later negative outcomes, or moderate current exposure to risk in terms of later outcomes.

A further methodological limitation of parental positivity research to date is the lack of clear definition and measurement of positivity. In a previous cross-sectional study, we explored the dimensions of this construct (Jess et al. 2017). Using Confirmatory Factor Analysis (CFA), we created a latent construct of maternal positivity from five single indicators: Parental Self-Efficacy (Hastings and Brown. 2002); parental general Satisfaction with Life (Diener et al. 1985); Family Satisfaction (Olson and Wilson. 1982); general Positive Affect (Watson et al. 1988); and Positive Perceptions of their child with ID (the Positive Contributions Scale: Behr et al. 1992). We used several criteria to evaluate model fit: the ratio of chi-square to degrees of freedom (CMIN/DF) under 2 (Tabachnick and Fidell. 2007), Root Mean Square Error of Approximation (RMSEA) under .05 (Browne and Cudeck 1993), and the Comparative Fit Index (CFI) above .95 (Hu and Bentler 1999). A confirmatory factor analysis indicated that these five indicators produced a well-fitting construct of positivity $\left(\chi^{2} / \mathrm{df}\right.$ ratio $=1.33, \mathrm{CFI}=1.00$, and $\left.\mathrm{RMSEA}=0.05\right)$. Thus, we were able to create one latent variable from five single indicators of positivity, which we then defined as 'maternal positivity'. Furthermore, we found that our latent variable of maternal positivity was negatively associated with maternal psychological distress and parenting stress, further confirming the construct's validity.

Although in our previous study we identified a negative association between maternal positivity and poor maternal mental health outcomes, the functions of maternal positivity were not examined. Therefore, the aim of the current study was to explore the function of maternal positivity both cross-sectionally and longitudinally. We included measures of children's behaviour and mental health problems as putative risk factors for maternal psychological adjustment. We examined both protective and compensatory functions (as defined earlier) for maternal positivity. In the absence of existing research, specific hypotheses were not examined.
Table 1 Demographic characteristics of mothers and children at Times 1 and 2

\begin{tabular}{lll}
\hline Variable & Time 1 & Time 2 \\
& $N(\%)$ & $N(\%)$ \\
\hline Total number of mothers & 135 & 110 \\
Mean age of mothers (range; & $39.45(23-57 ;$ & $39.92(23-57 ;$ \\
SD) & $7.23)$ & $7.23)$ \\
Married & $86(63.7 \%)$ & $73(66.4 \%)$ \\
Living with partner & $16(11.9 \%)$ & $13(11.8 \%)$ \\
Divorced & $33(24.4 \%)$ & $24(21.8 \%)$ \\
University or college education & $68(50.4 \%)$ & $57(51.8 \%)$ \\
Secondary school qualifications & $47(34.8 \%)$ & $42(38.2 \%)$ \\
No formal education & $20(14.8 \%)$ & $11(10 \%)$ \\
qualifications & & \\
Employment outside home & $65(48.1 \%)$ & $54(49.1 \%)$ \\
Not in employment & $70(51.9 \%)$ & $56(50.9 \%)$ \\
Full time employment & $18(13.3 \%)$ & $16(14.5 \%)$ \\
Part time employment & $47(34.8 \%)$ & $38(34.5 \%)$ \\
Mean number of children in & $2.2(1-5 ; 0.95)$ & $2.3(1-5 ; 2.28)$ \\
household (range; SD) & & \\
Mean age of children (range; & $10.02(3-18 ;$ & $9.94(3-18 ;$ \\
SD) & $4.11)$ & $4.16)$ \\
Girls & $46(34.1 \%)$ & $37(33.6 \%)$ \\
Boys & $89(65.9 \%)$ & $73(66.4 \%)$ \\
Autism + ID & $55(40.7 \%)$ & $42(38.2 \%)$ \\
Down's syndrome & $25(18.5 \%)$ & $23(20.9 \%)$ \\
Cerebral Palsy & $16(11.9 \%)$ & $15(13.6 \%)$ \\
Mixed aetiology & $39(28.9 \%)$ & $30(27.3 \%)$ \\
\hline & & \\
& &
\end{tabular}

\section{Method}

\section{Participants}

At Time 1 Participants were 135 mothers of children with severe ID (Table 1). Their ages ranged from 23 years to 57 years $(M=39.45$ years, $S D=7.23)$. A majority of the mothers were married or living with a partner $(n=102)$, although 33 (24.4\%) were divorced. The mothers were well educated: $68(50.4 \%)$ had a college or university education, $47(34.8 \%)$ had secondary school leaving qualifications, and $20(14.8 \%)$ mothers had no formal educational qualifications. Sixty-five mothers $(48.1 \%)$ had paid work outside the home and the remaining $70(51.9 \%)$ mothers were not in paid employment. Of the 65 mothers who were in paid employment, 18 (13.3\%) worked full-time and 47 (34.8\%) worked part-time. The majority of households had a total of one $(22.2 \%)$ or two $(42.2 \%)$ children living at home. Thirtyfive households had three $(25.9 \%)$ children at home, nine had four (6.7\%), and three had five (2.2\%) children living at home. One mother did not report on the total number of children living in the family home. 
There were 89 (65.9\%) boys and $46(34.1 \%)$ girls with ID, and diagnoses were based on parental reports. Fifty-five $(40.7 \%)$ children were reported as having an additional diagnosis of Autism, 25 (18.5\%) had Down's syndrome, 16 (11.9\%) had Cerebral Palsy, and 39 were a mixed aetiology ID group (28.9\%). Children's ages ranged from 3 to 18 years ( $M=10.02$ years; $S D=4.11$ years).

At Time 2 at one year follow-up 110 of the original 135 mothers participated. The follow-up sample were very similar to the original sample in terms of demographic characteristics (Table 1).

\section{Procedure}

The mothers included in the present study were those from a cross-sectional study (Hastings et al. 2005a, 2005b; Jess et al. 2017) who completed measures at Time 1 and 110 of those mothers completed follow-up measures 12 months after the initial data collection. All measures described below were gathered at the first data collection point (including the five positivity indicators contributing to the latent positivity construct). Maternal parenting stress and psychological distress (HADS) were also gathered at the first point of data collection and after 12 months had elapsed (Time 2).

Families were recruited through special schools for children with severe ID. Letters and information packs about the research were sent to more than 50 schools. Within the information pack was a response form and a paid reply envelope. Reply slips were received from 188 mothers and 72 fathers. Reply slips did not include information about the name of the child's school.

When response forms had been returned, separate questionnaire packs and consent forms were mailed to the primary caregiver. Families were offered a small payment for returning the questionnaires to recognise the time they had spent participating in the research. One year after the initial data collection, the families who took part at Time 1 were re-contacted to provide follow-up data.

\section{Measures}

In total, five measures were used in this study. In addition, we included a demographic questionnaire that identified sociodemographic characteristics reported in the Participants section.

The Behavior Problems Inventory (BPI-01; Rojahn et al. 2001) was used to measure child behaviour problems or "challenging behaviour". The BPI-01 is a 52-item instrument that measures self-injurious, stereotypic and aggressive behaviours in individuals with developmental disabilities. Self-injurious behaviours are defined as behaviours which can cause damage to the subject's own body
(Rojahn et al. 2001) such as hitting of the head or other body parts. Stereotypic behaviours are repeated body movements that are not part of a goal-directed act such as rocking and twirling and/or smelling objects. Aggressive or destructive behaviours are abusive deliberate attacks against other individuals or objects (Rojahn et al. 2001). This measure has two response scales, frequency and severity. We used the frequency scale only. Each item is scored on a five-point frequency scale, "never", "monthly", "weekly", "daily" and "hourly" ranging from a score of 0 (never) to 4 (hourly). Higher scores represent higher frequency. The alpha coefficient for the total BPI-01 frequency score was .94 in the present study.

The Reiss Scales for Children's Dual Diagnosis (Reiss and Valenti-Hein 1994) were used to measure children's behaviour problems and psychopathology as indicative of mental health difficulties. This is a 60-item measure designed to assess mental health in children with ID. Each item is scored on a three-point scale, "No Problem", "Problem", or "Major Problem". There are 10 subscales (attention deficit, anger, anxiety, conduct disorder, depression, autism, psychosis, self-esteem, somatoform and withdrawn behaviours). These scales can be used separately or summed to form a total problems score. For the present study, we used the total problems score. The Cronbach's alpha for the total score in the present sample was 0.95 .

Maternal positivity was a latent variable constructed using five indicators of positivity (see Introduction; Jess et al. 2017). It was designed to measure overall positivity in mothers of children with ID and is comprised of disabilityspecific, parenting specific and general measures of positivity. High scores indicate higher levels of positivity and low scores indicate lower levels of positivity. Sample items include: "The conditions of my life are excellent" (Satisfaction with Life Scale), "How satisfied are you with the amount of time you spend together as a family?" (Family Satisfaction Scale), "I consider my child to be the reason I am more productive" (Positive Contributions Scale), "How confident are you in parenting your child with special needs?" (Parenting Efficacy) and "Indicate to what extent you feel enthusiastic at this present moment" (Positive Affect Scale). Estimated regression-based factor scores for maternal positivity were extracted from AMOS 22 (Arbuckle 2013) where the construct was developed (Jess et al. 2017).

Maternal parenting stress, related to having a child with a disability in the family was measured using the Parent and Family Problems sub-scale of the Questionnaire on Resources and Stress- Friedrich short form (QRS-F; Friedrich et al. 1983). This subscale includes 20 items in total, coded as either true (0) or false (1). We excluded five items as they have been identified as a robust measure of depression (Glidden and Floyd 1997). This was to ensure 
that there was no overlap between the measures of stress and of mental health problems used in the present research. The QRS-F has good reliability when used with mothers of children with ID (Griffith et al. 2011). The KuderRichardson coefficient for the present sample was 0.86 .

Maternal psychological distress was assessed using the Hospital Anxiety and Depression Scales (HADS; Zigmond and Snaith 1983). This consists of two seven-item subscales that are rated from zero to three that measure levels of anxiety and depression. A unidimensional approach involves extracting a total score across all 14 items as a measure of psychological distress (Crawford et al. 2001). The HADS was initially developed to be used in outpatient settings but has been widely used in community-based research with parents of children with disabilities (e.g., Beck et al. 2004; MacDonald et al. 2010). The Cronbach's alpha for the psychological distress total score for the present sample was 0.88 .

\section{Data Analyses}

Initially, we ran bivariate correlations between the main study variables (Table 2). This was followed by a simple moderation analysis. PROCESS is a computational tool for path analysis-based moderation and mediation analysis. In this study, moderation analysis (model 1) was conducted using the PROCESS syntax (v2.16.3) developed for SPSS by Hayes (2012). Using this approach, moderation would be present if an interaction term between the putative moderator (maternal positivity) and risk factor (child behaviour problems) had a significant effect on maternal stress (parenting stress and psychological distress), thus potentially indicating a protective function of positivity. A significant main effect of positivity in the absence of a significant interaction term would indicate that positivity serves a compensatory function. The effect of maternal age, single parent status, employment status and maternal education (Time 1) on maternal stress was controlled for in the cross-sectional analysis. Maternal age, single parent status, employment status, maternal education and parenting stress/ psychological distress at Time 1 were controlled for in the longitudinal analysis. Child behaviour problems and maternal positivity were grand-mean centred prior to analysis to prevent multicollinearity. Bootstrapping (5000) was used to calculate standard errors and confidence intervals for all effects tested.

\section{Results}

We conducted two sets of analyses to address our research question and investigate the function of maternal positivity both cross-sectionally and longitudinally. Eight regression

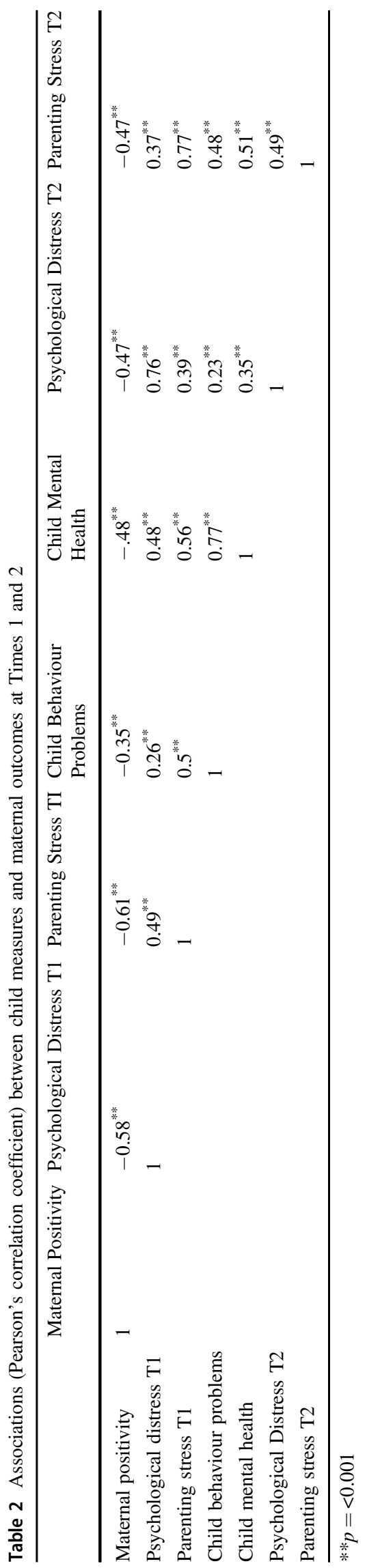


Table 3 Regression analysis examining the cross-sectional compensatory and protective functions of maternal positivity between child mental health problems and maternal stress
Table 4 Regression analysis examining the cross-sectional compensatory and protective functions of maternal positivity between child behaviour problems and maternal stress

\begin{tabular}{|c|c|c|c|c|c|c|c|c|}
\hline \multirow[t]{2}{*}{ Time 1 Predictor Variables } & \multicolumn{4}{|c|}{$\begin{array}{l}\text { Time } 1 \text { Maternal Psychological } \\
\text { Distress }^{\mathrm{a}}\end{array}$} & \multicolumn{4}{|c|}{ Time 1 Maternal Parenting Stress ${ }^{b}$} \\
\hline & $\beta$ & $p$ & LLCI & UCLI & $\beta$ & $p$ & LLCI & UCLI \\
\hline Child age & 0.020 & 0.885 & & & -0.307 & 0.048 & & \\
\hline Maternal age & -0.024 & 0.765 & & & 0.082 & 0.377 & & \\
\hline Single parent status & 1.372 & 0.014 & & & 0.092 & 0.883 & & \\
\hline Maternal education & -0.652 & 0.061 & & & 0.343 & 0.383 & & \\
\hline Maternal employment & 0.525 & 0.580 & & & -0.285 & 0.791 & & \\
\hline Maternal positivity & -0.766 & $<0.001$ & -1.028 & -0.505 & -0.899 & $<0 . .001$ & -1.194 & -0.603 \\
\hline Child mental health & 0.098 & 0.002 & 0.038 & 0.158 & 0.188 & $<0.001$ & 0.120 & 0.256 \\
\hline $\begin{array}{l}\text { Maternal positivity } \times \text { Child } \\
\text { mental health }\end{array}$ & -0.001 & 0.826 & -0.014 & 0.011 & 0.013 & 0.073 & -0.001 & 0.027 \\
\hline
\end{tabular}

$L L C$ Iower limit confidence interval, $U L C l$ upper limit confidence interval

${ }^{a}$ Model was significant: $F(8,118)=12.10, p=<0.001, R^{2}=0.45$

${ }^{\mathrm{b}}$ Model was significant: $F(8,115)=15.11, p=<0.001, R^{2}=0.72$

\begin{tabular}{|c|c|c|c|c|c|c|c|c|}
\hline \multirow[t]{2}{*}{ Time 1 Predictor Variables } & \multicolumn{4}{|c|}{$\begin{array}{l}\text { Time } 1 \text { Maternal Psychological } \\
\text { Distress }^{\text {a }}\end{array}$} & \multicolumn{4}{|c|}{ Time 1 Maternal Parenting Stress ${ }^{b}$} \\
\hline & $\beta$ & $p$ & LLCI & UCLI & $\beta$ & $p$ & LLCI & UCLI \\
\hline Child age & 0.102 & 0.489 & & & -0.232 & 0.152 & & \\
\hline Maternal age & 0.087 & 0.313 & & & 0.067 & 0.488 & & \\
\hline Single parent status & 1.259 & 0.034 & & & 0.086 & 0.893 & & \\
\hline Maternal education & -0.519 & 0.163 & & & 0.440 & 0.282 & & \\
\hline Maternal employment & 0.345 & 0.729 & & & -0.378 & 0.731 & & \\
\hline Maternal positivity & -0.937 & $<0.001$ & -1.197 & -0.677 & -0.993 & $<0.001$ & -1.278 & -0.708 \\
\hline Child behaviour problems & 0.019 & 0.303 & -0.017 & 0.056 & 0.107 & $<0.001$ & 0.067 & 0.146 \\
\hline $\begin{array}{l}\text { Maternal Positivity } \times \text { Child } \\
\text { behaviour problems }\end{array}$ & 0.005 & 0.226 & -0.003 & 0.012 & 0.011 & 0.008 & 0.003 & 0.019 \\
\hline
\end{tabular}

$L L C l$ lower limit confidence interval, $U L C l$ upper limit confidence interval

${ }^{a}$ Model was significant: $F(8,114)=9.60, p=<0.001, R^{2}=0.40$

${ }^{\mathrm{b}}$ Model was significant: $\mathrm{F}(8,111)=14.42, p=<0.001, R^{2}=0.51$ models were fitted in total, four cross-sectional and four longitudinal. Results of all analyses are summarised in Tables 3-6.

\section{Cross-Sectional Analyses}

For our first set of analyses, four regression models were fitted (Tables 3 and 4), varying the maternal outcome of focus (Time 1 parenting stress, or Time 1 psychological distress), and also varying the key child behaviour risk variable (BPI-01, or the Reiss Scales). All models were significant and the results of these analyses are summarised in Tables 3 and 4. Across all four regression models, maternal positivity only emerged as a significant moderator for one model: The interaction term between maternal positivity and frequency of child behaviour problems was significant when the outcome was parenting stress; $\beta=$ $0.008, t(111)=2.69, p=0.008$. Further output from the
PROCESS syntax showed the relationship between child behaviour problems and parenting stress at high levels of positivity $(\beta=0.15, t(111)=5.28, p=<0.001)$; mid-range levels $(\beta=0.11, t(111)=5.35, p=<0.001)$; and low levels $(\beta=0.06, t(111)=2.83, p=0.006)$. This pattern was not as predicted by a protective function model: parenting stress in mothers with the highest levels of positivity was most strongly associated with the level of the child's behaviour problems.

Maternal positivity did have a significant negative effect on maternal psychological distress and parenting stress across all four regression models (Tables 3 and 4). These main effect relationships between maternal positivity and maternal stress provide evidence that maternal positivity largely serves a compensatory function in these crosssectional analyses. Thus, mothers who reported high levels of maternal positivity reported lower levels of psychological distress and parenting stress, controlling for the effects of 
Table 5 Regression analysis examining the longitudinal compensatory and protective functions of maternal positivity between child mental health problems and maternal stress
Table 6 Regression analysis examining the longitudinal compensatory and protective functions of maternal positivity between child behaviour problems and maternal stress

\begin{tabular}{|c|c|c|c|c|c|c|c|c|}
\hline \multirow[t]{2}{*}{ Time 1 Predictor Variables } & \multicolumn{4}{|c|}{$\begin{array}{l}\text { Time } 2 \text { Maternal Psychological } \\
\text { Distress }^{\text {a }}\end{array}$} & \multicolumn{4}{|c|}{$\begin{array}{l}\text { Time } 2 \text { Maternal Parenting } \\
\text { Stress }^{\text {b }}\end{array}$} \\
\hline & $\beta$ & $p$ & LLCI & ULCI & $\beta$ & $p$ & LLCI & ULCI \\
\hline Child age & -0.041 & 0.752 & & & 0.163 & 0.063 & & \\
\hline Maternal age & 0.087 & 0.253 & & & -0.070 & 0.169 & & \\
\hline Single parent status & 0.398 & 0.468 & & & 0.488 & 0.176 & & \\
\hline Maternal education & 0.184 & 0.598 & & & 0.333 & 0.148 & & \\
\hline Maternal employment & -1.796 & 0.041 & & & -0.055 & 0.925 & & \\
\hline $\begin{array}{l}\text { Psychological distress/parenting } \\
\text { Stress at Time } 1\end{array}$ & 0.792 & $<0.001$ & & & 0.254 & $<0.001$ & & \\
\hline Maternal positivity & -0.056 & 0.695 & -0.339 & 0.227 & -0.129 & 0.180 & -0.320 & 0.061 \\
\hline Child mental health & 0.030 & 0.302 & -0.028 & 0.089 & 0.044 & 0.039 & 0.002 & 0.085 \\
\hline $\begin{array}{l}\text { Maternal positivity } \times \text { Child mental } \\
\text { health }\end{array}$ & 0.003 & 0.686 & -0.011 & 0.016 & -0.001 & 0.862 & -0.012 & 0.010 \\
\hline
\end{tabular}

$L L C l$ lower limit confidence interval, $U L C l$ upper limit confidence interval

${ }^{a}$ Model was significant: $F(9,93)=18.14, p=<0.001, R^{2}=0.64$

${ }^{\mathrm{b}}$ Model was significant: $F(9,84)=11.62, p=<0.001, R^{2}=0.56$

\begin{tabular}{|c|c|c|c|c|c|c|c|c|}
\hline \multirow[t]{2}{*}{ Time 1 Predictor Variables } & \multicolumn{4}{|c|}{$\begin{array}{l}\text { Time } 2 \text { Maternal Psychological } \\
\text { Distress }^{\mathrm{a}}\end{array}$} & \multicolumn{4}{|c|}{$\begin{array}{l}\text { Time } 2 \text { Maternal Parenting } \\
\text { Stress }^{\mathrm{b}}\end{array}$} \\
\hline & $\beta$ & $p$ & LLCI & UCLI & $\beta$ & $p$ & LLCI & UCLI \\
\hline Child age & -0.065 & .612 & & & 0.175 & 0.050 & & \\
\hline Maternal age & 0.109 & .155 & & & -0.078 & 0.135 & & \\
\hline Single parent status & 0.249 & .644 & & & 0.346 & 0.338 & & \\
\hline Maternal education & 0.234 & .496 & & & 0.295 & 0.212 & & \\
\hline Maternal employment & -0.517 & .080 & & & -0.064 & 0.915 & & \\
\hline $\begin{array}{l}\text { Psychological distress/ parenting } \\
\text { stress at Time } 1\end{array}$ & 0.777 & $<0.001$ & & & 0.264 & $<0.001$ & & \\
\hline Maternal positivity & -0.074 & 0.603 & -0.356 & 0.208 & -0.162 & 0.099 & -0.355 & 0.031 \\
\hline Child behaviour problems & 0.023 & 0.183 & -0.011 & 0.057 & 0.022 & 0.093 & -0.004 & 0.048 \\
\hline $\begin{array}{l}\text { Maternal positivity } \times \text { Child } \\
\text { behaviour problems }\end{array}$ & $<0.001$ & 0.842 & -0.008 & 0.009 & -0.004 & 0.210 & -0.010 & 0.002 \\
\hline
\end{tabular}

$L L C I$ lower limit confidence interval, $U L C I$ upper limit confidence interval

${ }^{a}$ Model was significant: $F(9,90)=17.34, p=<0.001, R^{2}=0.63$

${ }^{b}$ Model was significant: $F(9,81)=11.89, p=<0.001, R^{2}=0.57$ child behaviour problems/mental health and several socioeconomic indicators. All child mental health and behaviour problems were significant predictors of maternal outcomes. Child mental health had a positive main effect on both parenting stress, $\beta=0.19, t(115)=5.49, p=<001$, and psychological distress $\beta=0.10, t(118)=3.22, p=0.002$, whilst frequency of child behaviour problems only had a significant positive main effect on parenting stress, $\beta=$ $0.11, t(111)=5.35, p=<0.001$.

\section{Longitudinal analyses}

Four regression models were fitted (Tables 5 and 6) for the second set of analyses, varying the maternal outcome of focus (Time 2 parenting stress, or Time 2 psychological distress), and again varying child behaviour predictors. As with the first set of analyses, all regression models accounted for significant variance (Tables 5 and 6). Across all four longitudinal regression models, maternal positivity did not moderate the relationship between child variables at Time 1 and maternal stress at Time 2. Thus, there was no evidence that maternal positivity functioned as a moderator longitudinally. Furthermore, maternal positivity did not have a significant main effect on later parenting stress or later psychological distress. Therefore, in this study, we found no evidence that maternal positivity served either a compensatory or protective function longitudinally. In addition, child mental health had a positive main effect on 
later parenting stress, $\beta=0.04, t(84)=2.10, p=0.04$, but not on later psychological distress (Table 5) whilst frequency of child behaviour problems did not have a main effect relationship over time on either later parenting stress or later psychological distress.

\section{Discussion}

Research focusing on families raising children with ID has increasingly found that, despite challenges faced, positivity exists within these families. The present study addressed questions regarding the putative function of maternal positivity in mothers raising children with ID. We extended our original findings (Jess et al. 2017) by exploring the function of maternal positivity both cross-sectionally and longitudinally. Cross-sectional analysis found that maternal positivity had a direct association with maternal psychological distress and parenting stress. In addition, maternal positivity moderated the impact of child behaviour problems on maternal parenting stress. However, this interaction effect was not consistent with a putative protective function. Our findings suggest that at a cross-sectional level, maternal positivity functions mainly as a compensatory factor. Thus, mothers who reported high levels of maternal positivity reported lower levels of psychological distress and parenting stress, controlling for the effects of child behaviour/mental health problems and several socioeconomic indicators. Our findings are in concert with results from similar cross-sectional studies that demonstrate a main effect (compensatory) relationship (Lloyd and Hastings 2008) using single indicators of positivity. In this study, we have demonstrated this compensatory relationship using a robust latent measure of maternal positivity. We also found one moderation effect of positivity cross-sectionally using a latent measure of positivity. However, this moderated effect was not theoretically predicted and requires replication in future research.

Our longitudinal analysis revealed different results. Maternal positivity did not have a direct effect on later maternal psychological distress or parenting stress and there was no evidence that positivity might function as a moderator over time. Although maternal positivity had a compensatory function cross-sectionally, the direct effect of maternal positivity on maternal distress/stress were small which potentially explains why a compensatory function was not evident in our longitudinal analysis.

We are not aware of existing studies within the family disability literature that have examined the protective function of positivity variables longitudinally for mothers or parents generally. In the small number of cross-sectional analyses published to date (Blacher and Baker 2007; Weiss et al. 2015), single indicators of positivity were used. It is possible that we found different results longitudinally primarily because of the use of a latent positivity construct. Findings from this study offer a valuable contribution to the wider understanding of maternal positivity and how it functions to potentially improve the well-being of mothers raising a child with ID. As discussed earlier, mothers of children with ID often report poorer well-being than mothers of typically developing children therefore it is of great importance that research continues to understand which constructs may improve well-being and indeed how. Future longitudinal research should examine the functions of both single indicators and latent positivity constructs to more fully understand the potential for a protective function of positivity. Importantly, our cross-sectional findings remained even after controlling for demographic characteristics (maternal age, child age, education, employment and single parent status) that previous research has suggested to be correlates of maternal mental health (Blacher et al. 1997; Elgar et al. 2007; Emerson and Llewellyn 2008; Olsson and Hwang 2001).

Within disability family literature there is overwhelming evidence to support the theory that child behaviour problems have an inverse relationship with maternal mental health both cross-sectionally and longitudinally. Although not the specific focus of this study, it is worth noting that this was partially true for our longitudinal analyses as child mental health had a significant effect on later parenting stress. The results of our cross-sectional analyses were largely in concert with previous research confirming that child behaviour/mental health problems are correlates of maternal well-being.

Dealing with a child's behaviour problems is specific to the role of parenting whereas general psychological distress may be less affected by the challenges of raising a child with ID. This may explain why child behaviour problems had a significant effect on parenting stress but not on psychological distress. Similar results were found in a study of mothers of children with autism (Baker et al. 2011). Baker et al. found that whilst family adaptability, a similar construct to satisfaction with family, predicted a reduction of depressive symptomology, child behaviour problems did not have a significant effect on maternal depression.

In this study, child mental health problems had a negative main effect on both parenting stress and psychological distress cross-sectionally, and a longitudinal association with parenting stress. We have shown that a construct of maternal positivity, generated from five single indicators of positivity which are both disability and non-disability specific, is associated with reduced present maternal well-being albeit not over time. 


\section{Limitations and Future Research Directions}

A methodological limitation in the present study was that child behaviour problems and mental health measures were completed by mothers as were the measures of maternal well-being. Thus, our study suffered from a typical problem of shared source variance. The functions of positivity in future studies need to be explored in research designs where independent reports of child behaviour are obtained (e.g., from either the child's teacher or secondary caregiver). In addition, our sample size was modest. Therefore, our findings require replication before we can draw conclusions about the functions of maternal positivity. There is a possibility that maternal positivity has only a small association with other important variables in families of children with IDD potentially explaining why maternal positivity did not have a direct effect on maternal outcomes longitudinally. Dyches et al. (2012) also found small to very small effects for the association between positive parenting and child outcomes in ID families. However, it is clear that positive constructs do require further study because they do not seem to simply represent the absence of negative outcomes. Similar conclusions have been drawn in other research where a differential pattern of associations for maternal emotional disorder and positive maternal mental health were found (Totsika et al. 2011). Finally, the mothers were recruited via special schools supporting children with severe ID. Our findings might be specific to this sub-group and samples covering the full range of ID should be included in future research.

We have argued that, given definitional and measurement issues, utilising a latent positivity construct is a methodological improvement. However, it is important to recognise an associated limitation that the application of a latent maternal positivity construct to different participant samples is problematic. The construct of maternal positivity is dependent on the participant sample. Therefore, replication of our findings is particularly crucial when developing latent positivity constructs in different samples and reexamining the functions of parental positivity. Furthermore, exploration of single indicators should continue to be investigated to understand how they function longitudinally.

Consideration also needs to be given to the time frame of this study. Although a longitudinal design, one year between data collection points may not be sufficient to detect a protective or compensatory function of maternal positivity if in fact it exists. Future research could benefit from longer time points or collecting data over multiple waves. We would need to explore the function of positivity in larger and more representative samples as well as over longer periods of time.

\section{Compliance with Ethical Standards}

Conflict of Interest The authors declare that they have no conflict of interest.

Ethical Approval All procedures performed in studies involving human participants were in accordance with the ethical standards of [The University of Warwick] research committee and with the 1964 Helsinki declaration and its later amendments or comparable ethical standards

Informed Consent Informed consent was obtained from all individual participants included in the study.

\section{References}

Anthony, L. G., Anthony, B. J., Glanville, D. N., Naiman, D. Q., Waanders, C., \& Shaffer, S. (2005). The relationships between parenting stress, parenting behaviour and preschoolers' social competence and behaviour problems in the classroom. Infant and Child Development, 14, 133-154.

Arbuckle, J. (2013). AMOS 22. User's Guide. Chicago, IL: SmallWaters Corporation.

Baker, B. L., Blacher, J., \& Olsson, M. B. (2005). Preschool children with and without developmental delay: behaviour problems, parents' optimism and well-being. Journal of Intellectual Disability Research, 49, 575-590.

Baker, B. L., McIntyre, L. L., Blacher, J., Crnic, K., Edelbrock, C., \& Low, C. (2003). Pre-school children with and without developmental delay: behaviour problems and parenting stress over time. Journal of Intellectual Disability Research, 47, 217-230.

Baker, J. K., Seltzer, M. M., \& Greenberg, J. S. (2011). Longitudinal effects of adaptability on behavior problems and maternal depression in families of adolescents with autism. Journal of Family Psychology, 25(4), 601.

Beck, A., Hastings, R. P., Daley, D., \& Stevenson, J. (2004). Prosocial behaviour and behaviour problems independently predict maternal stress. Journal of Intellectual and Developmental Disability, 29, 339-349.

Behr, S. K., Murphy, D. L., \& Summers, J. A. (1992). User's Manual: Kansas Inventory of Parental Perceptions (KIPP): Measures of Perceptions of Parents who Have Children with Special Needs. Beach Center on Families and Disability, Beach Center: University of Kansas..

Benzies, K. M., Harrison, M. J., \& Magill-Evans, J. (2004). Parenting stress, marital quality, and child behavior problems at age 7 years. Public Health Nursing, 21, 111-121.

Blacher, J., \& Baker, B. L. (2007). Positive impact of intellectual disability on families. American Journal on Mental Retardation, $112,330-348$.

Blacher, J., Begum, G. F., Marcoulides, G. A., \& Baker, B. L. (2013). Longitudinal perspectives of child positive impact on families: Relationship to disability and culture. American Journal on Intellectual and developmental disabilities, 118, 141-155.

Browne, M. W., \& Cudeck, R. (1993). Alternative ways of assessing model fit. Sage Focus editions, 154, 136-136.

Blacher, J., Lopez, S., Shapiro, J., \& Fusco, J. (1997). Contributions to depression in Latina mothers with and without children with retardation: Implications for caregiving. Family Relations: Interdisciplinary Journal of Applied family Studies, 46, 325-334.

Crawford, J. R., Henry, J. D., Crombie, C., \& Taylor, E. P. (2001). Normative data for the HADS from a large non-clinical sample. British Journal of Clinical Psychology, 40, 429-434. 
Diener, E. D., Emmons, R. A., Larsen, R. J., \& Griffin, S. (1985). The satisfaction with life scale. Journal of personality Assessment, 49, $71-75$.

Donenberg, G., \& Baker, B. L. (1993). The impact of young children with externalizing behaviors on their families. Journal of Abnormal Child Psychology, 21, 179-198.

Dunn, M. E., Burbine, T., Bowers, C. A., \& Tantleff-Dunn, S. (2001). Moderators of stress in parents of children with autism. Community Mental Health Journal, 37, 39-52.

Dyches, T. T., Smith, T. B., Korth, B. B., Roper, S. O., \& Mandleco, B. (2012). Positive parenting of children with developmental disabilities: A meta-analysis. Research in Developmental Disabilities, 33, 2213-2220.

Ekas, N. V., Lickenbrock, D. M., \& Whitman, T. L. (2010). Optimism, social support, and well-being in mothers of children with autism spectrum disorder. Journal of Autism and developmental Disorders, 40, 1274-1284.

Elgar, F. J., Mills, R. S., McGrath, P. J., Waschbusch, D. A., \& Brownridge, D. A. (2007). Maternal and paternal depressive symptoms and child maladjustment: The mediating role of parental behavior. Journal of Abnormal Child Psychology, 35, 943-955.

Emerson, E. (2003). Mothers of children and adolescents with intellectual disability: social and economic situation, mental health status, and the self-assessed social and psychological impact of the child's difficulties. Journal of Intellectual disability Research, 47, 385-399.

Emerson, E., \& Llewellyn, G. (2008). The mental health of Australian mothers and fathers of young children at risk of disability. Australian and New Zealand Journal of Public Health, 32, 53-59.

Fraser M. W., Galinsky M. J., \& Richman J. M. (1999). Risk, protection, and resilience: Toward a conceptual framework for social work practice. Social Work Research, 23, 131-143.

Friedrich W. N., Greenberg M. T., \& Crnic K. (1983). A short form of the Questionnaire on Resources and Stress. American Journal of Mental Deficiency, 88, 41-48.

Gardner, J., \& Harmon, T. (2002). Exploring resilience from a parent's perspective: A qualitative study of six resilient mothers of children with an intellectual disability. Australian Social Work, 55, $60-68$.

Glidden, L. M., Billings, F. J., \& Jobe, B. M. (2006). Personality, coping style and well-being of parents rearing children with developmental disabilities. Journal of Intellectual Disability Research, 50(12), 949-962.

Glidden, L. M., \& Floyd, F. J. (1997). Disaggregating parental depression and family stress in assessing families of children with developmental disabilities: A multisample analysis. American Journal on Mental Retardation, 102, 250-266.

Griffith, G. M., Hastings, R. P., Oliver, C., Howlin, P., Moss, J., Petty, J., \& Tunnicliffe, P. (2011). Psychological well-being in parents of children with Angelman, Cornelia de Lange and Cri du Chat syndromes. Journal of Intellectual Disability Research, 55, 397-410.

Halstead E., Ekas N., Hastings R. P., \& Griffith G. M. (2018). Associations between resilience and the well-beingof mothers of children with autism spectrum disorder and other developmental disabilities. Journal of Autism and Developmental Disorders, 48, 1108-1121.

Hassall, R., Rose, J., \& McDonald, J. (2005). Parenting stress in mothers of children with an intellectual disability: The effects of parental cognitions in relation to child characteristics and family support. Journal of Intellectual Disability Research, 49, 405-418.

Hastings, R. P. (2016). Chapter Six-Do Children With Intellectual and Developmental Disabilities Have a Negative Impact on Other Family Members? The Case for Rejecting a Negative Narrative.
International Review of Research in Developmental Disabilities, 50, 165-194.

Hastings, R. P., Allen, R., McDermott, K., \& Still, D. (2002). Factors related to positive perceptions in mothers of children with intellectual disabilities. Journal of Applied Research in Intellectual disabilities, 15, 269-275.

Hastings, R. P., Beck, A., \& Hill, C. (2005a). Positive contributions made by children with an intellectual disability in the family Mothers' and fathers' perceptions. Journal of Intellectual Disabilities, 9, 155-165.

Hastings, R. P., \& Brown, T. (2002). Behavior problems of children with autism, parental self-efficacy, and mental health. American Journal on Mental retardation, 107, 222-232.

Hastings, R. P., Kovshoff, H., Ward, N. J., Degli Espinosa, F., Brown, T., \& Remington, B. (2005b). Systems analysis of stress and positive perceptions in mothers and fathers of pre-school children with autism. Journal of Autism and developmental Disorders, 35, 635.

Hastings, R. P., \& Taunt, H. M. (2002). Positive perceptions in families of children with developmental disabilities. American Journal on Mental retardation, 107, 116-127.

Hautmann, C., Eichelberger, I., Hanisch, C., Plück, J., Walter, D., \& Döpfner, M. (2015). Association between parental emotional symptoms and child antisocial behaviour: What is specific and is it mediated by parenting? International Journal of Behavioral Development, 39, 43-52.

Hayes, A. F. (2012). PROCESS: A versatile computational tool for observed variable mediation, moderation, and conditional process modeling [White paper]. Retrieved from http://www.afhayes. com/public/process2012.pdf.

Heiman, T. (2002). Parents of children with disabilities: Resilience, coping, and future expectations. Journal of developmental and Physical disabilities, 14, 159-171.

Herring, S., Gray, K., Taffe, J., Tonge, B., Sweeney, D., \& Einfeld, S. (2006). Behaviour and emotional problems in toddlers with pervasive developmental disorders and developmental delay: associations with parental mental health and family functioning. Journal of Intellectual Disability Research, 50, 874-882.

Hu L. T., \& Bentler P. M. (1999). Cutoff criteria for fit indexes in covariance structure analysis: Conventionalcriteria versus new alternatives. Structural equation modeling: a multidisciplinary journal, 6, 1-55.

Jess M., Hastings R. P., \& Totsika V. (2017). The construct of maternal positivity in mothers of children withintellectual disability. Journal of Intellectual Disability Research, 61, 928-938.

Jones, L., Hastings, R. P., Totsika, V., Keane, L., \& Rhule, N. (2014). Child behavior problems and parental well-being in families of children with autism: the mediating role of mindfulness and acceptance. American Journal on Intellectual and developmental disabilities, 119, 171-185.

Kuhn, J. C., \& Carter, A. S. (2006). Maternal self-efficacy and associated parenting cognitions among mothers of children with autism. American Journal of Orthopsychiatry, 76, 564-575.

Lloyd, T., \& Hastings, R. P. (2008). Psychological variables as correlates of adjustment in mothers of children with intellectual disabilities: cross-sectional and longitudinal relationships. Journal of Intellectual Disability Research, 52(1), 37-48.

Lloyd, T. J., \& Hastings, R. (2009). Hope as a psychological resilience factor in mothers and fathers of children with intellectual disabilities. Journal of Intellectual Disability Research, 53, 957-968.

Lounds, J., Seltzer, M. M., Greenberg, J. S., \& Shattuck, P. T. (2007). Transition and change in adolescents and young adults with autism: Longitudinal effects on maternal well-being. American Journal on Mental Retardation, 112, 401-417. 
Luthar, S. S. (1991). Vulnerability and resilience: A study of high-risk adolescents. Child Development, 62, 600.

Luthar, S. S., \& Zigler, E. (1991). Vulnerability and competence: a review of research on resilience in childhood. American Journal of Orthopsychiatry, 61, 6.

Lyons, A. M., Leon, S. C., Phelps, C. E. R., \& Dunleavy, A. M. (2010). The impact of child symptom severity on stress among parents of children with ASD: The moderating role of coping styles. Journal of Child and Family Studies, 19, 516-524.

MacDonald, E. E., Hastings, R. P., \& Fitzsimons, E. (2010). Psychological acceptance mediates the impact of the behaviour problems of children with intellectual disability on fathers' psychological adjustment. Journal of Applied Research in Intellectual Disabilities, 23, 27-37.

Minnes, P., Perry, A., \& Weiss, J. A. (2015). Predictors of distress and well-being in parents of young children with developmental delays and disabilities: the importance of parent perceptions. Journal of Intellectual Disability Research, 59, 551-560.

Morgan J., Robinson D., \& Aldridge J. (2002). Parenting stress and externalizing child behaviour. Child \& Family Social Work, 7, 219-225.

Neece, C., \& Baker, B. (2008). Predicting maternal parenting stress in middle childhood: The roles of child intellectual status, behaviour problems and social skills. Journal of Intellectual Disability Research, 52, 1114-1128.

Neece, C. L., Green, S. A., \& Baker, B. L. (2012). Parenting stress and child behavior problems: A transactional relationship across time. American Journal on Intellectual and Developmental Disabilities, 117, 48-66.

Olsson, M. B., \& Hwang, C. P. (2001). Depression in mothers and fathers of children with intellectual disability. Journal of Intellectual Disability Research, 45, 535-543.

Olson, D. H., \& Wilson, M. (1982, 1989). Family Satisfaction. In D. H. Olson (Ed.) Families: What Makes Them Work. Newbury Park, CA: Sage Publishing.

Pit-ten Cate, I. (2003). Positive gain in mothers of children with physical disabilities. Unpublished Doctoral Dissertation, University of Southampton, UK.

Reiss, S., \& Valenti-Hein, D. (1994). Development of a psychopathology rating scale for children with mental retardation. Journal of Consulting and Clinical Psychology, 62, 28.
Rojahn, J., Matson, J. L., Lott, D., Esbensen, A. J., \& Smalls, Y. (2001). The Behavior Problems Inventory: An instrument for the assessment of self-injury, stereotyped behavior, and aggression/ destruction in individuals with developmental disabilities. Journal of Autism and developmental Disorders, 31, 577-588.

Rutter, M. (1985). Resilience in the face of adversity. Protective factors and resistance to psychiatric disorder. The British Journal of Psychiatry, 147, 598-611.

Salari, R., Wells, M. B., \& Sarkadi, A. (2014). Child behaviour problems, parenting behaviours and parental adjustment in mothers and fathers in Sweden. Scandinavian Journal of Public Health, $42,547-553$.

Sinclair, V. G., \& Wallston, K. A. (2004). The development and psychometric evaluation of the Brief Resilient Coping Scale. Assessment, 11(1), 94-101.

Tabachnick, B. G., \& Fidell, L. S. (2007). Using Multivariate Statistics. 5th ed New York, NY: Allyn and Bacon.

Totsika, V., Hastings, R. P., Emerson, E., Berridge, D. M., \& Lancaster, G. A. (2011). Behavior problems at 5 years of age and maternal mental health in autism and intellectual disability. Journal of Abnormal Child Psychology, 39, 1137.

Vilaseca, R., Ferrer, F., \& Olmos, J. G. (2014). Gender differences in positive perceptions, anxiety, and depression among mothers and fathers of children with intellectual disabilities: a logistic regression analysis. Quality \& Quantity, 48, 2241-2253.

Watson, D., Clark, L. A., \& Tellegen, A. (1988). Development and validation of brief measures of positive and negative affect: the PANAS scales. Journal of personality and Social Psychology, 54, 1063.

Wehmeyer, M. L., Shogren, K. A., Shogren, K. A., Singh, N. N., \& Uyanik, H. (2017). Strengths-based approaches to intellectualand developmental disabilities. In K. Shogren, M. Wehmeyer, N. N. Singh (eds.) Handbook of positivepsychology in intellectual and developmental disabilities. (pp. 13-21). New York: Springer.

Weiss, J. A., MacMullin, J. A., \& Lunsky, Y. (2015). Empowerment and parent gain as mediators and moderators of distress in mothers of children with autism spectrum disorders. Journal of Child and Family Studies, 24, 2038-2045.

Zigmond, A. S., \& Snaith, R. P. (1983). The hospital anxiety and depression scale. Acta psychiatrica scandinavica, 67, 361-370. 